\title{
What Are We Studying? An overview of HCl's curricula in Brazilian Software Engineering Undergraduate Programs
}

\author{
Bruno Braga Medeiros \\ Federal University of Pampa \\ Av. Tiaraju, 810 - Alegrete / RS \\ brunobragamedeiros@gmail.com
}

\author{
Jean Felipe P. Cheiran \\ Federal University of Pampa \\ Av. Tiaraju, 810 - Alegrete / RS \\ jeancheiran@unipampa.edu.br
}

\begin{abstract}
Studying and applying Human-Computer Interaction (HCI) concepts on Software Engineering (SE) programs is meaningful when society demands more useful, accessible and pleasant software applications to be made. However, teaching $\mathrm{HCI}$ is perceived as a challenging task in an interdisciplinary aspect. Therefore, this study aims to understand what Brazilian SE undergraduate students are being taught on HCI courses. In order to accomplish it, we applied a content analysis methodology on 21 distinct syllabi from 15 universities, which resulted on the categorization of 28 teaching topics. The outcome of this work allow us to visualize the most HCI concepts seen on Brazilian SE programs: Design, Interaction Styles \& Paradigms, System Evaluation, and Usability. Moreover, we presented discussions related to the HCI knowledge being offered on SE undergraduate programs.
\end{abstract}

\section{Author Keywords}

Human-Computer Interaction; Software Engineering curricula; Teaching; HCI.

\section{ACM Classification Keywords}

Social and professional topics Software engineering education

\section{INTRODUCTION}

Human-Computer Interaction (HCI) knowledge is known for its direct effect on the quality in use and, consequently, its importance to the end user. The HCI field has some particularities, one of them is that $\mathrm{HCI}$ is an interdisciplinary field that involves distinct courses, such as Cognitive Psychology, Graphical Design, Ergonomics, Computer Science, among others [2]. Due to the fact that HCI is a broad field, it is important to investigate what contents of knowledge are being exposed to students.

Teaching HCI in Brazil has been studied over the years [1, 2, 3]; however, in the best of our knowledge, none of the works presented has focus on the investigation of how Brazilian universities teach HCI in SE programs. Thus, the main goal of

Permission to make digital or hard copies of all or part of this work for personal or classroom use is granted without fee provided that copies are not made or distributed for profit or commercial advantage and that copies bear this notice and the full citation on the first page. Copyrights for components of this work owned by others than the author(s) must be honored. Abstracting with credit is permitted. To copy otherwise, or republish, to post on servers or to redistribute to lists, requires prior specific permission and/or a fee. Copyright 2018 SBC.

IHC 2018, Anais Estendidos do XVII Simpsio Brasileiro sobre Fatores Humanos em Sistemas Computacionais

Outubro 22-26, 2018, Belém, Brasil

PÔSTERES VIRTUAIS E DEMOS this work is to present the scenery of what subjects related to the HCI field are taught in Brazilian universities on SE undergraduate programs. In order to achieve it, a content analysis methodology was used [4].

\section{RESEARCH PROCESS AND CONDUCTION}

This study is based on documentary research [5] and content analysis [4]. This section aims to present an overview of the performed Content Analysis methodology, which is composed by 5 steps: Preparation; Unitization; Categorization; Description; and Interpretation.

For accomplishing this study, we mapped the public and private Brazilian Universities with Software Engineering programs. The search was performed on the National Institute for Educational Studies and Research "Anísio Teixeira" (INEP). A total of 33 universities with SE programs were found. From the 13 public universities, we had access to 12 curricula; from the 20 private universities, we had access to 5 curricula.

The Preparation step involves finding the data that best represent the investigated subject. For accomplishing this, the 17 curricula found were read, and $21 \mathrm{HCI}$ related courses were gathered: 18 required courses and 3 elective courses.

After preparing all the data needed to accomplish the research goal, we performed the Unitization step. The previous data was deeply inspected and transformed into units of content, in order to be categorized and analyzed later. This process was executed on all of the 21 courses and it generated 324 units.

Categorization is used to group the units based on specific categorization criteria - semantic content of units. Moreover, quality criteria are established [4]: (a) categories must be homogeneous, mutually exclusive and exhaustive; (b) categorization criteria must remain the same through categorization; and (c) categories must be meaningful and useful to the research goals. This step produced 28 categories.

Description involves naming categories according to the units belonging to them and performing descriptive analysis. Table 1 presents the information related to the amount of universities, courses and units in each one of the categories (table's columns show categories names created on the categorization step, total of universities related to categories ${ }^{1}$; totality of courses related to categories, and totality of units belonging to each one of the categories).

\footnotetext{
${ }^{1}$ Different campi on the same university are treated as one university.
} 


\begin{tabular}{|l|l|l|l|}
\hline Category & Univ. & Courses & Units \\
\hline Design & 13 & 18 & 67 \\
Interaction Styles \& Paradigms & 11 & 12 & 44 \\
System Evaluation & 11 & 13 & 30 \\
Usability & 10 & 12 & 29 \\
Human Factors & 8 & 9 & 21 \\
Development & 9 & 11 & 17 \\
Requirements Engineering & 5 & 5 & 15 \\
Web \& Multimedia & 6 & 8 & 12 \\
Accessibility & 6 & 7 & 12 \\
Introduction to HCI & 7 & 8 & 9 \\
User Experience & 3 & 5 & 9 \\
Patterns & 6 & 8 & 8 \\
Peripherals & 6 & 7 & 8 \\
Cultural Aspects & 5 & 5 & 7 \\
Historical Evolution & 2 & 3 & 7 \\
Architecture & 5 & 5 & 5 \\
Tools & 4 & 5 & 5 \\
Mobile Technologies & 2 & 2 & 4 \\
Cognition & 3 & 3 & 3 \\
Multidisciplinarity & 2 & 2 & 2 \\
Semiotics & 2 & 2 & 2 \\
Help Systems & 1 & 1 & 2 \\
Communicability & 1 & 1 & 1 \\
Computer Vision & 1 & 1 & 1 \\
Quality & 1 & 1 & 1 \\
Special Topics & 1 & 1 & 1 \\
Theoretical Approaches & 1 & 1 & 1 \\
Virtual Reality & 1 & 1 & 1 \\
\hline
\end{tabular}

Table 1. Categories and the respective quantity of associated universities, courses and units.

The final step of content analysis, Interpretation, is known for the activity of comprehending the categorized data. The data exposed at Table 1 was analyzed and interpreted ${ }^{2}$.

\section{DISCUSSION}

Based on the emerged categories and the content analysis as a whole, we raised some topics on HCI teaching in SE to be discussed with the HCI Brazilian community.

Recent approached areas in curricula. Some categories represent technologies with recent advances, e.g. "Mobile Technologies" and "Virtual Reality"; thus, these categories may not be composed of a large amount of units because some universities have not incorporated them into curriculum.

Do it! The categories with the largest amount of units tend to be more practical than theoretical (e.g. "Design" and "System Evaluation") or to expose knowledge highly related to practical environments (e.g. "Interaction Styles \& Paradigms" and "Usability"). This may occur because SE programs tend to work with hands-on methodologies rather than theoretical approaches. However, the "Development" category, which is extremely related to practical tasks, does not partake of this aspect. A possible reason is that SE programs tend to distribute software development through curricula and some SE programs have specific environments to development practices $^{3}$.

\footnotetext{
${ }^{2}$ In order to propose a friendlier visualization of the data, a WordCloud image was designed. The image is uploaded on https://ibb.co/nrGfOJ

${ }^{3}$ SE program at Federal University of Pampa and Pontifical Catholic University of Rio Grande do Sul use problem solving courses and Experimental Agency of SE for development practices.
}

Professor's expertise. In some cases a specific subject is deeply studied on a SE program because of the professor's field. Thus, some categories have a significant number of units connected to few universities. Example of this are the "User Experience" and "Historical Evolution" categories: these categories have respectively 9 and 7 units that are connected only to 3 and 2 distinct universities.

Is my interface good? One of the most appreciating findings is that the knowledge related to planning, executing and analyzing how to evaluate a software is significantly studied on Brazilian SE programs. As it can be seen at Table 1, the category "System Evaluation" is at a high position. Other categories, such as "Usability", "Accessibility" and "Web \& Multimedia", also have units that include the evaluation keyword, leading to a total of 37 units of evaluation.

\section{CONCLUSION AND FUTURE WORK}

Aiming to provide the first scenery of what Brazilian HCI courses teach on SE programs, we investigated Brazilian universities and applied a content analysis methodology on the curricula found. The HCI teaching has already been studied by Silveira and Prates [6], resulting in a proposal of generic program recommendations, and by Boscarioli et alli [3]. However, the study of HCI teaching on SE undergraduate programs is a recent topic of knowledge; therefore, our work is pioneer in the field of HCI teaching in this context.

For future work, it would be thought-provoking to investigate HCI topics in non HCI courses (once SE programs' courses tend to be cross-disciplinary) and if there are regional tendencies on the way SE programs conducts HCI knowledge.

\section{REFERENCES}

1. Fabiane Benitti and Leonardo Sommariva. 2012. Investigando o ensino de IHC no contexto da computação: o que e como é ensinado?. In III Workshop sobre Ensino de IHC. Cuiabá, 33-38.

2. Silvia Bim, Raquel Prates, Milene Silveira, and Marco Winckler. 2011. Ensino de IHC - Atualizando as Discussões sobre a Experiência Brasileira. In XIX Workshop sobre Educação em Computação. Natal.

3. Clodis Boscarioli, Milene Silveira, Raquel Prates, Silvia Bim, and Simone Barbosa. 2014. Currículos de IHC no Brasil: Panorama Atual e Perspectivas. In XXII Workshop sobre Educação em Computação. Brasília, 1294-1303.

4. Roque Moraes. 1999. Análise de Conteúdo. Revista Educação 22, 37 (1999), 7-32.

5. Antonio Severino. 2010. Metodologia do Trabalho Científico (23rd ed.). Cortez, São Paulo, SP, Brazil.

6. Milene Silveira and Raquel Prates. 2007. Uma Proposta da Comunidade para o Ensino de IHC no Brasil. In XV Workshop sobre Educação em Computação. Rio de Janeiro, 76-84. 